\title{
Práticas visuais com alunos surdos: o visual e o escrito nas aulas de matemática ${ }^{1}$
}

\author{
Daiane Kipper \\ Universidade de Santa Cruz do Sul - UNISC \\ daianekipper@hotmail.com
}

\section{Cláudio José de Oliveira}

Universidade de Santa Cruz do Sul - UNISC

coliver@unisc.br

\section{Adriana da Silva Thoma}

Universidade Federal do Rio Grande do Sul- UFRGS

asthoma@terra.com.br

\begin{abstract}
Resumo
O presente artigo tem por objetivo problematizar uma prática matemática visual realizada em uma escola pública localizada no estado do Rio Grande do Sul, a partir da seguinte questão: quais implicações curriculares emergem das práticas matemáticas visuais produzidas por alunos surdos? Para tal empreendimento, o mesmo apoia-se nos estudos sobre o currículo escolar (SILVA, 2005) em suas interlocuções com a Etnomatemática (KNIJNIK, 2010, 1997; KNIJNIK et al., 2012) e os Estudos Surdos (PERLIN, 2004; THOMA e KRAEMER, 2009; THOMA, 2012). O material de pesquisa foi produzido a partir de uma oficina de frações, intitulada As Frações e o tempo, e excertos de um diário de campo. Os resultados da investigação apontam possibilidades de tornar a Matemática uma disciplina mais próxima da comunidade surda, para que os alunos surdos lidem com esse conhecimento e produzam práticas visuais matemáticas que possam constituir-se em um legado para esses sujeitos.
\end{abstract}

Palavras-chave: Etnomatemática. Currículo escolar. Estudos Surdos. Pedagogia Visual.

\section{Visual practices with deaf students: the visual and the written in mathematics classes}

\footnotetext{
Abstract

This paper aims to problematize a visual mathematical practice in a public school in the state of Rio Grande do Sul by considering the following question: which curriculum implications emerge from the visual mathematical practices produced by deaf students? In order to do so, we have relied on

${ }^{1} \mathrm{O}$ presente artigo é uma versão ampliada e revisada do trabalho intitulado Práticas visuais nas aulas de Matemática com alunos surdo, publicado nos anais da $37^{\mathrm{a}}$ Reunião Nacional da Associação Nacional de Pós-Graduação e Pesquisa em Educação.
} 
studies of school curriculum (SILVA, 2005) in their interlocutions with Ethnomathematics (KNIJNIK, 2010, 1997; KNIJNIK et al., 2012) and Deaf Studies (PERLIN, 2004; THOMA \& KRAEMER, 2009; THOMA, 2012). The research material was produced in a fraction workshop called The fractions and the time, and excerpts from a field journal. The results have pointed out possibilities of approximating Mathematics to the deaf community so that deaf students deal with this knowledge and produce visual mathematics practices that can become a legacy to those subjects.

Keywords: Ethnomathematics. School curriculum. Deaf Studies. Visual Pedagogy.

\section{A Matemática nos currículos escolares}

A matemática enquanto conhecimento disciplinar implicado no currículo das instituições escolares tem como principal função a formação de um ser racional, e ao mesmo tempo selecionar as melhores mentes. Em outras palavras, selecionar os sujeitos que dominam o conhecimento matemático selecionado por alguns para fazer parte do que chamamos de currículo escolar.

Logo, os sujeitos que não dominam essa matemática são instituídos como incapazes de pensar matematicamente. Nesse âmbito, o currículo é um dispositivo capaz de governar tanto alunos quanto professores. Quando falamos em governo, refiramo-nos ao governo no sentido dado por Foucault, "é estruturar o eventual campo de ação dos outros" (FOUCAULT, 1995, p. 288).

A 'arte de governar' atualmente permeia as nossas instituições, e entre elas, a escola. $\mathrm{O}$ gerenciamento da população se dá principalmente nas instituições de ensino, onde se produzem sujeitos autônomos, empreendedores, proativos, solidários e capazes de gerenciar suas próprias vidas. O currículo escolar é organizado com esse objetivo, que vai ao encontro da arquitetura das escolas, da distribuição das classes, dos horários e das trocas de períodos. Dessa forma, se dá a produção de espécies desejáveis e a regulação dos corpos.

O currículo escolar, aqui entendido em uma perspectiva pós-critica, segundo Silva, é um dispositivo escolar que contribui para governar como se pretende. Silva (2005, p. 15) explica que "o currículo é sempre o resultado de uma seleção: de um universo mais amplo de conhecimentos e saberes seleciona-se aquela parte que vai constituir, precisamente, o currículo". Ele apresenta-se como uma seleção do que se deve ser ensinado, o qual tem por objetivo formar pessoas. Ainda nas palavras do autor, "um currículo busca precisamente modificar as pessoas que vão 'seguir' aquele currículo" (SILVA, 2005, p. 15).

E nesse currículo está implicada a Matemática enquanto disciplina que tem como principal função a produção de sujeitos racionais. A disciplina de Matemática não existiu desde a criação da instituição escolar, mas foi constituída de acordo com interesses políticos e econômicos de cada época. 
Nessa perspectiva, implicamo-nos a pensar na matemática como um campo do currículo que também compõe a Educação Bilíngue ${ }^{2}$ para surdos. Para tal empreendimento, situamos nossas análises no campo dos Estudos Surdos, que se constituiu como um programa de pesquisa em educação, "onde as identidades, as línguas, os projetos educacionais, a história, a arte, as comunidades e as culturas surdas são focalizadas e entendidas a partir da diferença, a partir do seu reconhecimento político" (SKLIAR, 2010, p. 5).

Para a comunidade surda, o canal visual é o meio pelo qual esses sujeitos acessam o mundo, assim como se dão as suas perspectivas em relação aos acontecimentos e conhecimentos. A experiência $^{3}$ visual insere-se numa perspectiva cultural, em que o sujeito surdo é compreendido pela sua diferença. Perlin (2004) afirma que a cultura assume centralidade na constituição da subjetividade e da identidade da pessoa. As marcas da diferença moldam as identidades surdas de acordo com a receptividade cultural assumida pelo sujeito. "A cultura surda é o lugar para o sujeito surdo construir sua subjetividade de forma a assegurar sua sobrevivência e a ter seu status quo diante das múltiplas culturas, múltiplas identidades" (PERLIN, 2004, p. 78, grifado no original).

A escola de surdos apresenta-se como um espaço de encontro, sendo o primeiro espaço de convivência de muitos surdos com outros surdos.

$\mathrm{Na}$ escola, as práticas curriculares acabam sempre instaurando ações de disciplinamento da conduta e dos corpos surdos, e visam produzir sujeitos governados a ser e estar em uma sociedade majoritariamente ouvinte. Em grande parte das vezes, o discurso da surdez como falta a ser corrigida toma uma posição de superioridade no currículo, buscando a normalização dos sujeitos surdos através da aproximação desses de um modelo ouvinte, branco, empreendedor, solidário etc., para que possam circular e participar da sociedade sendo produtivos e responsáveis por si mesmos e pelo outro, independente do espaço institucional em que a educação acontece (escola comum ou escola bilíngüe) (THOMA, 2012, p. 212).

Nesse contexto, entendemos que a Matemática, enquanto disciplina escolar que compõe o currículo escolar, está "diretamente implicada na produção de subjetividades, como uma das engrenagens da maquinaria escolar que funciona na produção dos sujeitos escolares” (KNIJNIK et al., 2012, p. 25).

Skliar (2010) afirma que uma educação e uma escola possível devem referir-se à criação de políticas linguísticas, de identidades comunitárias e de cultura pensadas a partir dos surdos, de como se representa e reconstrói o próprio processo de educação. A experiência visual é apontada como

\footnotetext{
2 “A Educação Bilíngue de surdos envolve a criação de ambientes linguísticos para aquisição da Libras como primeira língua (L1) por crianças surdas, no tempo de desenvolvimento linguístico esperado e similar ao das crianças ouvintes, e a aquisição do português como segunda língua (L2)" (THOMA et al., 2014, p. 6).

${ }^{3}$ Neste estudo estamos conceituando a experiência a partir de Larrosa (2004, p. 154), para o qual essa se constitui como aquilo "que nos passa, ou o que nos acontece, ou o que nos toca. Não o que passa ou o que acontece, ou o que toca, mas o que nos passa, o que nos acontece ou nos toca. A cada dia passam muitas coisas, porém, ao mesmo tempo quase nada nos passa, dir-se-ia que tudo que passa está organizado para que nada nos passe."
} 
um imperativo na compreensão do surdo enquanto sujeito pertencente a uma cultura. Estamos presenciando um tempo de lutas dos surdos "que se voltam para a educação em sinais e pela cultura visual nas escolas" (THOMA, 2012, p. 213).

Nessa perspectiva, o presente artigo ${ }^{4}$ tem por objetivo problematizar uma prática matemática visual - em formato de Oficina - realizada com alunos surdos de uma escola referência em educação de surdos. As discussões deste texto apoiam-se na seguinte questão: Quais implicações curriculares emergem das práticas matemáticas visuais produzidas por alunos surdos? A pesquisa foi realizada em uma escola localizada no Vale do Rio Pardo, no estado do Rio Grande do Sul, e teve como sujeitos seis alunos surdos de uma turma do $6^{\circ}$ ano do Ensino Fundamental.

O material de pesquisa foi produzido a partir de uma Oficina de Frações, intitulada As Frações e o tempo, excertos do diário de campo, material escrito produzido pelos alunos surdos e registros fotográficos. Com base no material de pesquisa, organizamos este estudo, que se inicia com a presente seção e divide-se em outras duas, intituladas: Das oficinas: As Frações e o tempo, $O$ Visual e o Escrito nas aulas de Matemática: experiências de uma matemática visual para surdos e Considerações Finais: por uma educação matemática visual para surdos.

\section{Das oficinas: As Frações e o tempo...}

Ao iniciar este estudo, o método foi delineando-se de acordo com o que o ato de pesquisar nos exigia. Não havia uma forma certa ou errada, mas inúmeras formas e possibilidade de realizar a pesquisa e decidir os caminhos da investigação era a nossa incumbência como professores pesquisadores. Esse caminho suscitou e se configurou na Oficina de Frações como possibilidade a ser experimentada nessa investigação.

Aqui, em As Frações e o tempo, descrevemos alguns elementos do que podemos denominar de uma prática visual em formato de oficina realizada com a turma de alunos surdos do $6^{\circ}$ ano do Ensino Fundamental referida anteriormente, onde a primeira autora deste texto atua como professora de Matemática. Os sujeitos da pesquisa consistiram em seis alunos surdos, sendo três do sexo feminino e três do sexo masculino, os quais nomeamos como: Paulo, José, Fernando, Paola, Micaela e Karolina ${ }^{5}$. A faixa etária desses sujeitos variava entre 11 e 13 anos de idade.

A oficina consistiu em uma prática visual que foi realizada no período de 11 a 17 de julho de 2014, com duração de 9 horas-aula. Para a realização da mesma, exploramos o funcionamento do relógio analógico, explicitando a relação entre minutos e horas. Primeiramente, mostramos os

\footnotetext{
${ }^{4}$ Este estudo é um recorde de uma pesquisa de Mestrado realizada pela primeira autora, sob a orientação do segundo e co-orientação da terceira autora do presente artigo.

${ }^{5}$ Os nomes são fictícios.
} 
minutos de uma hora, construindo com eles as multiplicações por cinco e explicando com base em um relógio analógico de parede que entre os valores numéricos havia cinco minutos.

$\mathrm{Na}$ sequência, trabalhamos a relação das horas na sua forma expressa em frações com o denominador doze. Com o mesmo relógio, demonstramos aos alunos a quantidade de minutos que compõem uma hora, construindo com eles as multiplicações do número indicado por cinco. E concomitantemente a relação das horas no formato de frações com o denominador doze. Na maior parte das aulas, trabalhamos com o relógio de parede e com cópias impressas do relógio analógico, mas as atividades não estavam resultando na compreensão dos alunos em relação às horas e às frações e às horas.

Ainda com o relógio, revisamos a relação entre horas e minutos. Para tal, desenhamos um relógio no quadro, e novamente fizemos referência às frações, demonstrando as relações entre um quarto de hora e quinze minutos; meia hora e trinta minutos; três quartos de hora e quarenta e cinco minutos.

Por fim, realizamos um ditado das horas com o relógio: o horário era mostrado e no caderno eles deveriam escrever as horas e os minutos marcados no mesmo. Entretanto, não obtivemos sucesso com a atividade, pois somente Karolina estava compreendendo a proposta, e os alunos Paulo, Fernando e Paola faziam referência somente aos minutos, enquanto José e Micaela demostraram não compreender a atividade.

Com um relógio de parede analógico, fomos deslocando o ponteiro dos minutos sobre os números e calculando com eles o valor referente aos minutos, visto que cada intervalo entre os números do relógio correspondia ao intervalo de 5 minutos. No quadro, desenhamos o relógio e pintamos as partes correspondentes a: 1 hora $=60$ minutos; $1 / 2$ hora $=30$ minutos; $1 / 4$ hora $=15$ minutos; $1 / 12$ hora $=5$ minutos.

Na sequência, explanamos que o relógio continha ao todo doze partes e o ponteiro maior dos minutos apontava para a contagem dos espaços menores entre os números de 1 a 12 , expressando no quadro as seguintes relações, entre frações e minutos:

$$
\begin{aligned}
& \frac{1}{12}=5 \mathrm{~min} ; \frac{2}{12}=10 \mathrm{~min} ; \frac{3}{12}=15 \mathrm{~min} ; \frac{4}{12}=20 \mathrm{~min} ; \frac{5}{12}=25 \mathrm{~min} ; \frac{6}{12}=30 \mathrm{~min} ; \frac{7}{12}=35 \mathrm{~min} ; \\
& \frac{8}{12}=40 \mathrm{~min} ; \frac{9}{12}=45 \mathrm{~min} ; \frac{10}{12}=50 \mathrm{~min} ; \frac{11}{12}=55 \mathrm{~min} ; \frac{12}{12}=60 \mathrm{~min} .
\end{aligned}
$$

Em seguida, realizamos atividades individuais. Com o relógio de parede em mãos, chamávamos os alunos e perguntávamos para cada um o horário que estava sendo marcado no relógio. No primeiro momento, solicitamos que apenas observassem o ponteiro referente aos minutos, realizando essa atividade em duas rodadas. 
Posteriormente, explicamos que o ponteiro menor indicava o valor referente à hora, e não havia necessidade de multiplicar o valor por cinco. Para verificar a compreensão dos alunos em relação às horas e minutos, realizamos um ditado com o relógio de parede. Percebemos que os alunos estavam fazendo referência apenas aos minutos, os quais escreviam antes da palavra 'horas', com exceção da aluna Karolina, a qual já apresentava conhecimentos prévios. Já o José não completou nenhuma das atividades, afirmando que não estava entendendo, que 'não sabia o que era para fazer'.

No dia 15 de julho de 2014, desenhamos um relógio no quadro, e novamente fizemos referência às frações, demonstrando as relações entre: um quarto de hora e quinze minutos; meia hora e trinta minutos; três quartos de hora e quarenta e cinco minutos. Antes de realizarmos um novo ditado, elaboramos outra atividade visual com os mesmos. No relógio de parede, marcamos o ponteiro dos minutos sobre o número 4, e solicitamos que os mesmos respondessem quantos minutos o ponteiro estava marcando. Nessa atividade apenas a aluna Karolina disse o valor correspondente a marcação do ponteiro.

Percebemos que as atividades realizadas durante a oficina não estavam colaborando para a compreensão dos alunos em relação ao conhecimento das horas, em relógio analógico. Então decidimos construir com os alunos o desenho de um relógio analógico em um papel pardo. Para a realização dessa atividade, utilizamos uma régua de um metro, papel pardo, caneta colorida, lápis, borracha, cola, tampinhas de metal e um transferidor de madeira. Construímos um relógio com 80 centímetros de diâmetro e depois dividimos em quatro partes iguais e na sequência em doze partes iguais. Ao redor do relógio, escrevemos os valores referentes às horas e posteriormente colamos 60 tampinhas de garrafa referente à 60 minutos. Na sequência, colocamos sobre o relógio, dois ponteiros: das horas e dos minutos.

Figura 1 - Relógio elaborado pelos alunos do $6^{\circ}$ ano do EF

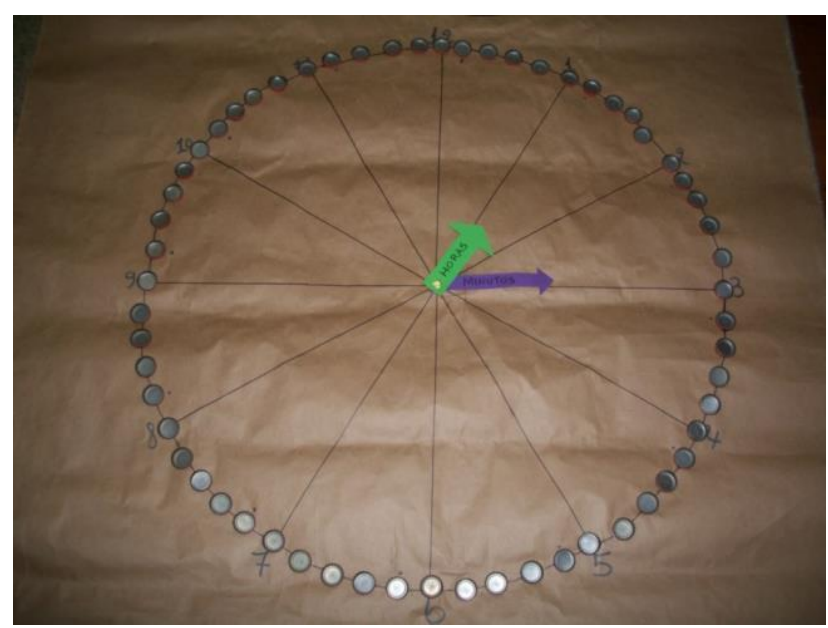

Fonte: Arquivo pessoal. 
A atividade de construir um relógio proporcionou a experiência dos alunos com a geometria e com a trigonometria. A estratégia de construção de um relógio foi pensada no intuito de possibilitar a experiência prática e visual dos alunos. Campello (2008) afirma que a visualidade pode constituir-se como um discurso, pela possibilidade de ser produzida por signos e ao mesmo tempo produzi-los. "As experiências da visualidade produzem subjetividades marcadas pela presença da imagem e pelos discursos viso-espaciais provocando novas formas de ação do nosso aparato sensorial, uma vez que a imagem não é somente uma forma de ilustrar um discurso oral" (CAMPELlO, 2008, p. 11). No currículo escolar, os processos de aprender e ensinar pela interpretação de signos visuais implica uma ressignificação da relação do sujeito com o conhecimento, tendo em vista que a visualidade produz subjetividades.

Para a construção do relógio de forma a contemplar o visual, primeiramente foi construído um círculo no papel pardo com 70 centímetros de diâmetro, dividido em doze partes iguais. Levamos para a sala de aula o círculo pronto apenas para os alunos visualizarem a atividade que seria proposta, e que serviria de referência para a elaboração do relógio. Pedimos para que todos se aproximassem da atividade, para a demonstração das marcações do raio no primeiro quadrante. Primeiro solicitamos que realizassem a divisão do diâmetro $(80 \mathrm{~cm})$ para encontramos o valor do raio. A aluna Karolina realizou mentalmente o cálculo, enquanto os demais alunos realizaram a divisão na calculadora. Assim que descobriram o valor do raio, demonstramos com a régua a marcação do mesmo, em curtos intervalos, e depois os unimos, formando assim a quarta parte do relógio. Os alunos foram organizados em dupla, a fim de realizar a mesma atividade nos outros quadrantes.

Finalizado o contorno da circunferência, explicamos que precisávamos dividir cada um dos quadrantes em três partes iguais. Para isso, utilizamos um transferidor grande (para desenhar no quadro). Colocando o transferidor de 180 graus sobre o centro da circunferência, explicamos que a circunferência completa continha 360 graus, a metade 180 graus e a metade da metade continha 90 graus. Para melhor compreensão dos alunos, solicitamos que eles realizassem as divisões na calculadora, e para a constatação dos resultados demostrávamos o ângulo no relógio. Em seguida, solicitamos que dividissem o ângulo de 90 graus por três. Obtiveram como resposta 30 graus. Então, demonstramos no primeiro quadrante como deveriam ser realizadas as marcações, traçando no quadrante outros dois raios. E na sequência realizaram a tarefa nos demais quadrantes.

Com a circunferência dividida em 12 partes iguais, a aluna Karolina fez referência ao denominador doze. Então solicitamos que ela escrevesse no quadro as frações correspondentes ao relógio e depois fomos em conjunto colocando as tampinhas sobre cada intervalo de hora e escrevendo no quadro o valor referente a cada fração. Um a um, os alunos foram realizando a tarefa 
de colocar os números de tampinhas até o valor indicado e posteriormente contavam quantas tampinhas havia.

Durante a realização dessa atividade, percebemos que para os alunos Paulo e Karolina não havia mais a necessidade de contar as tampinhas para saber os minutos, pois os mesmos já estavam estabelecendo a relação dos minutos quanto à multiplicação pelo número 5. Já os demais alunos contavam sempre o número de tampinhas para saber o valor dos minutos, mesmo que o ponteiro estivesse sobre os valores $1,2,3,4,5,6,7,8,9,10,11$ e 12 .

Após completarmos o relógio com todas as tampinhas, questionamos os alunos sobre o funcionamento da hora e dos minutos, apresentando para os mesmos dois ponteiros: um menor para as horas e outro maior para os minutos. Colocamos sobre o relógio o ponteiro menor (referente às horas) sobre o número dez (10 horas) e ponteiro maior (referente aos minutos) sobre o número cinco (25minutos).

Durante a atividade, os alunos questionavam sobre o valor a ser considerado para cada ponteiro. Paulo e Karolina demostraram entendimento sobre o funcionamento do relógio, desde as primeiras horas colocadas sobre ele. Já os demais, pouco a pouco foram compreendendo o funcionamento. Tinham muitas dúvidas no início, então solicitamos que sempre contassem o número de tampinhas para o ponteiro maior e escrevessem apenas o número que o ponteiro menor indicava. Demostramos para eles que o ponteiro menor poderia estar entre dois números, e que nesse caso deveriam levar em consideração o número menor.

Em determinado momento, José começou a contagem dos minutos no sentido inverso, logo os demais alunos chamaram a atenção dele, sinalizando para o mesmo que estava errado. Fernando estava errando ao contar as tampinhas, por falta de atenção. José e Micaela demoraram mais tempo para compreender a relação, mas no decorrer das atividades, ambos demostraram entendimento em relação ao funcionamento do relógio. Todos os alunos vibravam ao encontrar os resultados.

\section{O Visual e o Escrito nas aulas de Matemática: experiências de uma matemática visual para surdos}

Na oficina As Frações e o tempo, a construção de um relógio proporcionou aos alunos a compressão do funcionamento de um relógio analógico, bem como a relação do tempo com as frações. Também possibilitou aos mesmos a experiência com os conhecimentos geométricos que estavam implícitos e explícitos na atividade. Assim, a atividade desenvolvida possibilitou a experiência com os conteúdos, pois passou a fazer sentido para os alunos surdos. José e Micaela, que 'silenciaram' nas outras atividades, participaram da proposta 'expondo suas mãos' com os valores marcados no relógio, em relação à hora e aos minutos. Mais uma vez, a oficina provou 
movimento, e assim saímos de uma rigidez que permitiu, junto aos alunos, explorar a matemática visual $^{6}$, praticando-a e não somente visualizando-a, provocando a experiência.

Assim, a construção do relógio apresentou-se como uma atividade que contemplou a experiência visual desses sujeitos no currículo escolar, currículo esse que parece habituado à linearidade. E assim nos proporcionou a abertura de uma 'nova fenda': a discussão entre o visual e o escrito na Matemática. Para pensar sobre o modo como temos nos apropriado do conhecimento matemático em nossos currículos escolares, apoiamo-nos em estudos realizados pelo campo da Etnomatemática, que vem sendo compreendido por Knijnik et al. (2012, p. 28) como “[...] uma "caixa de ferramenta" que possibilita analisar os discursos que instituem as Matemáticas Acadêmica e Escolar e seus efeitos de verdade" .

Nessa perspectiva, a referida autora salienta que na perspectiva da Etnomatemática existem outras formas de produzir significados matemáticos além da Matemática Escolar e da Matemática Acadêmica. E essas outras formas de produzir conhecimento matemático são manifestadas por outros grupos culturais, como: as diferentes nações indígenas, os distintos grupos profissionais e agricultoras e agricultores (KNIJNIK, 1997) e, acrescentaríamos, entre outros, a matemática visual praticada pelos surdos.

Nesse âmbito, há estudos que realizam uma discussão entre o oral e o escrito em relação a outros grupos culturais. Assim, abre-se a possibilidade de realizar, de forma análoga, uma discussão entre o visual e o escrito no contexto da educação bilíngue para surdos, ao entender

[...] a educação matemática como um campo do currículo também implicado na construção de subjetividades, produzidas não em um terreno neutro e desinteressado, mas, ao contrário, em um terreno onde certos grupos acabam por impor o seu modo de raciocinar e a sua matemática como a única racionalidade possível, talvez possamos problematizar, por exemplo, a relação entre a escrita e a oralidade na matemática escolar. A escrita marcada pelo formalismo das sentenças matemáticas e dos algoritmos hegemonicamente se faz presente na matemática escolar, essa matemática escolar que, num processo de recontextualização, toma emprestado da matemática acadêmica - a produzida pelos matemáticos na academia - sua linguagem formal, abstrata [...] (KNIJNIK, 2010, p. 72).

As frações e o tempo rompe a linearidade, possibilitando-nos olhar novamente para o que já era visto e repensarmos sobre a forma como os conteúdos estão organizados nos currículos escolares das nossas escolas e quais sujeitos esses currículos querem produzir. E abrem espaço para o visual nas aulas de Matemática, visual tanto em relação ao desenho do relógio e a produção do mesmo em imagem para a compreensão das frações e das horas por parte dos alunos, quanto em relação à comunicação visual dos conhecimentos matemáticos em Libras. Durante a atividade, os

\footnotetext{
${ }^{6}$ Neste estudo, estamos compreendendo como visual a matemática desenvolvida na Língua Brasileira de Sinais (primeira língua dos surdos) e o escrito o que se refere à matemática na modalidade escrita da Língua Portuguesa (segunda língua dos surdos).
} 
conteúdos matemáticos, que de forma recorrente são ministrados em língua portuguesa em escrita própria (símbolos e signos) da Matemática, foram trabalhados de forma dinâmica e em Libras. E, assim, conteúdos referentes à geometria, à trigonometria, a unidades de medida, e às frações e aos números decimais foram se interconectando, não sendo necessário o estabelecimento de uma ordem.

Romper com a linearidade do currículo escolar e pensá-lo a partir de experiências de uma matemática visual para surdos apresentou-se como um desafio para nós, professores pesquisadores. Desafio que nos possibilitou abrir a "caixa" ${ }^{7}$. Entretanto, para caminhar pela pesquisa e movimentarse por essa investigação, se faz necessário abrir algumas fissuras, que denominamos como 'fendas'. 'Fendas' que se abrem quando assumimos lentes teóricas para olhar para além da caixa e nos possibilitam ver de forma diferente o que víamos antes.

\section{Considerações Finais: por uma educação matemática visual para surdos}

"Pensar incomoda como andar à chuva. Quando o vento cresce e parece que chove mais" (PESSOA, 2014, p. 16). Pensar... é o que nos movimenta nessa investigação, ao incomodar-nos e desacomodar-nos. Entre pensamentos, aventuramo-nos por entre os números, letras e sinais e, assim, fomos constituindo este estudo que não quer se esgotar. Finalizamos com palavras, mas não findamos os pensamentos incomodados. E assim, aventuramo-nos e arriscamo-nos a 'abrir a caixa' e nos despir daquilo que já haviam nos ensinado, ou melhor, dizendo, nos engessado. 'Abrir a caixa', no sentido de abrir-nos para nos estranhar diante do mundo. Nesse embalo, nos instigamos a pensarmos em outras possibilidades para a disciplina Matemática no currículo escolar de alunos surdos.

A mesma agora é 'bagunçada' em um currículo que tenta ser bilíngue. Em que o conhecimento matemático vai tomando outras formas, onde signos escritos tentam ser sinalizados, misturando-se por entre número, letras e sinais.

Assim, pelas fissuras, procuramos outros modos de pensar, rompendo com os padrões fixos e imutáveis da Matemática Escolar para atravessá-los com as práticas visuais. E, assim, buscamos torná-la uma disciplina mais próxima da comunidade surda, para que os alunos surdos lidem com esse conhecimento e produzam práticas visuais matemáticas, e que essa produção seja um legado para a comunidade surda. Não estamos afirmando que os surdos irão produzir uma matemática própria, mas que os mesmos podem produzir práticas visuais para lidar com esse conhecimento, visto que no desenvolvimento das atividades, de forma estratégica, convencionaram-

\footnotetext{
${ }^{7}$ Neste estudo, estamos utilizando com metáfora da 'caixa', sendo a 'caixa' o local seguro que se apresenta como a formação inicial de professor de Matemática.
} 
se sinais para determinadas palavras e conceitos. E para essa produção se faz necessário um currículo escolar que possibilite movimentos mais dinâmicos para a aprendizagem.

\section{Referências}

CAMPELLO, A. R. S. Pedagogia visual na educação dos surdos-mudos. 2008. 169 f. Tese (Programa de Pós-Graduação de Educação) - Universidade Federal de Santa Catarina, Florianópolis, 2008.

FOUCAULT, M. O sujeito e o poder. In: DREYFUS, Hubert L.; RABINOW, Paul. Michel Foucault, uma trajetória filosófica: para além do estruturalismo e da hermenêutica. Rio de Janeiro: Forense Universitária, 1995. p. 273-295.

LARROSA, J. Linguagem e educação depois de Babel. Belo Horizonte: Autêntica, 2004.

KIPPER, D.; OLIVEIRA, C. J. Práticas visuais nas aulas de matemática com alunos surdos. In: REUNIÃO NACIONAL DA ASSOCIAÇÃO NACIONAL DE PÓS-GRADUAÇÃO E PESQUISA EM EDUCAÇÃO, 37., 2015, Florianópolis. Anais... Flosrianópolis: Copiart, 2015. p. 1-17. Disponível em: <http://37reuniao.anped.org.br/wp-content/uploads/2015/02/Trabalho-GT194386.pdf>. Acesso em: 20 out. 2015.

KNIJNIK, G. Educação Matemática, currículo e diferença cultural. In: LOPES, M. C.; FABRIS, E. H. (Orgs.). Aprendizagem \& inclusão: implicações curriculares. Santa Cruz do Sul: EDUNISC, 2010. p. 69-86.

. As novas modalidades de exclusão social: trabalho, conhecimento e educação. Revista Brasileira de Educação, São Paulo, n. 4, p. 35-42, jan./abr. 1997. et al. Etnomatemática em movimento. Belo Horizonte: Autêntica, 2012.

PERLIN, G. T. T. O lugar da cultura surda. In: THOMA, A. S.; LOPES, M. C. (Orgs.). A invenção da surdez: cultura, alteridade, identidade e diferença no campo da educação: EDUNISC, 2004. p. 73-82.

PESSOA, F. O guardador de rebanhos. Portugal: Centro Atlântico, 2014.

SILVA, T. T. Documentos de identidade: uma introdução às teorias do currículo. 2. ed. Belo Horizonte: Autêntica, 2005. 156 p.

SKLIAR, C. Os estudos surdos em educação: problematizando a normalidade. In: . (Org.). A surdez: um olhar sobre as diferenças. Porto Alegre: Mediação, 2010. p. 7-32.

THOMA, A. S. A afirmação da diferença e da cultura surda no cenário da educação inclusiva: desafios para o currículo. In: SARAIVA, K.; MARCELLO, F. A. Estudos culturais e educação: desafios atuais. Canoas: Ulbra, 2012. p. 205-215.

et al. Relatório sobre a Política Linguística de Educação Bilíngue - Língua Brasileira

de Sinais e Língua Portuguesa. 2014. Elaborado por Grupo de Trabalho, designado pelas Portarias n 1.060 e n ${ }^{\circ}$ 91/2013 do MEC/SECADI. Disponível em:

<www.bibliotecadigital.unicamp.br/document/?down=56513>. Acesso em: 13 set. 2014. 